\section{Discussion}

Many clinical signs are taught to successive generations of medical students, yet their importance and reliability have not been as carefully assessed as have more recent aids to diagnosis. The three principal methods used in this study to distinguish direct hernias from indirect hernias were chosen because they seemed to be the most likely to give an unambiguous result. Men below the age of 30 were excluded to prevent any observer bias towards a diagnosis of indirect inguinal hernias, which are well known to preponderate in that age group.

Our results indicated that although the methods enable correct prediction of the nature of the hernia to be made more often than by chance, even considering the relative incidence of the types of hernia, they do not enable a diagnosis to be made with complete accuracy. Two observers in agreement were much more accurate in their diagnosis than when in dispute, but since agreement occurred in just over half the cases the overall accuracy remained disappointing. Agreement was reached probably only when the signs were more evident.

At the start of this study the opinion of the participating surgeons was that the inguinal occlusion test was the most helpful method of distinguishing between the types of hernia. This did not prove so in practice. Two reasons for this were encountered during the study. Firstly, the internal ring may be so distended by a large hernia sac that the occluding finger fails to control the ring, and the hernia is adjudged as direct. Secondly, a laterally placed funicular direct hernia may be controlled by a finger slightly displaced medially, leading to a diagnosis of an indirect hernia sac.

These findings may be of little clinical importance where the policy is to operate on all inguinal hernias. Occasionally, however, it has been implied that it is acceptable to treat direct hernias conservatively because they seldom strangulate. ${ }^{5} 8$ Here a policy of management has been constructed on flimsy grounds because our study shows that the diagnosis of direct hernias is suspect.

While we advocate medical judgment based on skill and experience, where the possibility of assessing these arts objectively arises we suggest that a disservice is done to clinical science by not heeding the results of such a study. At a time when there are graat pressures on the student curriculum any exercise that can be shown to be of little relevance or of poor reliability, however hallowed by usage, is best disregarded. We therefore believe that there is no further merit in attempting to distinguish between indirect and direct inguinal hernias.

\section{References}

${ }^{1}$ Rains AJH, Ritchie HD, eds. Bailey and Love's short practice of surgery. 17th ed. London: Lewis, 1977.

2 Ellis H, Calne RY. Lecture notes on general surgery. 5th ed. Oxford: Blackwell, 1977.

3 Macfarlane DA, Thomas LP. Textbook of surgery. 4th ed. Edinburgh: Churchill Livingstone, 1977.

- Browse N. An introduction to the symptoms and signs of surgical disease. London: Arnold, 1978.

5 Ellis H. Inguinal hernia. Br $\mathcal{f}$ Hosp Med 1970;4:9-14.

- Clain A, ed. Hamilton Bailey's physical signs in clinical surgery. 15th ed. Bristol: Wright, 1973.

${ }^{7}$ Moore PG, Shirely EA, Edwards DE. Standard statistical calculations. 2nd ed. London: Pitman, 1972.

8 Kettlewell MGW. Lumps in the groin and scrotum. Brf Hosp Med 1973; 9:724-30.

(Accepted 15 February 1980)

\title{
Management of acute stroke in the elderly: preliminary results of a controlled trial
}

\author{
W M GARRAWAY, A J AKHTAR, R J PRESCOTT, L HOCKEY
}

\section{Summary and conclusions}

A randomised controlled trial compared the management of elderly patients with acute stroke in a stroke unit and medical units. A significantly higher proportion of patients discharged from the stroke unit (78 of the 155 admitted) were assessed as independent compared with patients discharged from medical units (49 of the 152 admitted). The intensive use of treatment that might have been implied by creating a stroke unit did not occur, although almost all the patients admitted to the unit received occupational therapy while only $47 \%$ of the patients admitted to medical units received occupational therapy. The delay before starting treatment was significantly shorter in the stroke unit.

\footnotetext{
University Department of Community Medicine, Edinburgh EH9 1DW

W M GARRAWAY, MSC, MFCM, senior lecturer
}

Royal Victoria Hospital, Edinburgh EH4 2DN

A J AKHTAR, MB, FRCP, consultant physician in geriatric medicine

Medical Computing and Statistics Unit, Edinburgh EH8 9AG

R J PRESCOTT, MSC, PHD, senior lecturer

University Department of Nursing Studies, Edinburgh EH8 9JT L HOCKEY, PHD, SRN, director, nursing research unit
Results of this trial show that the stroke unit improved the natural history of stroke by increasing the proportion of patients who were returned to functional independence.

\section{Introduction}

Stroke is a major burden on the community ${ }^{1}$ and will remain so while stroke prevention is in its infancy. ${ }^{2}$ The indications for therapeutic or surgical intervention after stroke remain few, and efforts to improve prognosis in the period immediately after onset by providing intensive care facilities have been unsuccessful.4 Attention should therefore be shifted to establishing the most effective means of rehabilitating patients with stroke.

While general agreement exists on the principles of rehabilitation that should be adopted, little or none exists on how to organise the staff and facilities for stroke rehabilitation. ${ }^{5}$ This was recognised by a report of the Royal College of Physicians, which recommended setting up a few stroke units based on existing departments of geriatric medicine, neurology, or rehabilitation, to act as focal points for developing facilities and

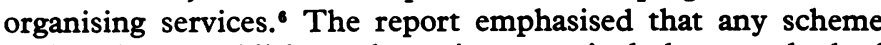
designed to establish stroke units must include a method of assessing their value. We report the preliminary findings of such an assessment, which was undertaken to test the hypothesis that a higher proportion of patients may be returned to independence 
after admission to a stroke unit rather than a medical unit. We also attempted to assess the use of physiotherapy, occupational therapy, and speech therapy as an essential first step to establishing their relative importance in stroke rehabilitation.

\section{Methods}

The study was a randomised controlled trial, with patients being admitted either to a stroke unit or to one of 12 medical units on call for emergency admissions. The stroke unit, which was created by changing the function of a ward of 15 beds within a geriatric unit, had been operating for one year before the study began and had evolved an operational policy that was initially based on the work of Isaacs.? Almost all general practitioners serving a catchment population of 470000 agreed to notify appropriate patients aged 60 years and over, using as the definition of stroke a focal neurological deficit of presumed vascular origin that had been present for at least six hours but no longer than three days. Medical staff were on call 24 hours a day to undertake home visits to confirm the practitioner's diagnosis. Patients were eligible to participate in the study if they were conscious and had an established or developing hemiplegia at the time of assessment.

The outcome of the acute phase of rehabilitation was assessed when discharge was imminent or at a cut-off point of 16 weeks after admission. The assessment was made by using a purpose-built activities of daily living unit designed to reproduce the home or any other place to which patients were being discharged. Patients were classified as independent if they could get in and out of bed, dress, were mobile indoors, could perform toileting and personal hygiene, cook a simple hot meal, feed themselves, and control their environment without human assistance; and dependent if they required human assistance to complete at least one activity or failed to carry out the activity altogether. The planning, use, and validation of the activities of daily living unit have been fully described elsewhere. ${ }^{8}$

\section{Results}

Altogether, 155 patients were admitted to the stroke unit and 156 patients to medical units from October 1975 to April 1978. Four

TABLE I-Outcome at end of acute phase of rehabilitation (figures are numbers (\%) of patients)

\begin{tabular}{lllcc}
\hline & & & $\begin{array}{c}\text { Stroke unit } \\
(\mathbf{n}=155)\end{array}$ & $\begin{array}{c}\text { Medical units } \\
(\mathbf{n}=152)\end{array}$ \\
\hline $\begin{array}{l}\text { Independent } \\
\text { Dependent }\end{array}$ & $\cdots$ & $\cdots$ & $78(50)$ & $49(32)$ \\
Dead $\quad \cdots$ & $\cdots$ & $\cdots$ & $47(31)$ & $60(40)$ \\
\hline
\end{tabular}

Significance of difference: $\mathrm{p}<0.01\left(x^{2}=10.49, \mathrm{df}=2\right)$.

TABLE II-Use of physiotherapy (figures are means $\pm S E$ )

\begin{tabular}{|c|c|c|c|c|}
\hline & & $\begin{array}{c}\text { Stroke unit } \\
(n=155)\end{array}$ & $\begin{array}{l}\text { Medical units } \\
(n=152)\end{array}$ & $\begin{array}{l}\text { Significance of } \\
\text { differences }\end{array}$ \\
\hline \multicolumn{5}{|c|}{ No $(\%)$ of patients receiving any } \\
\hline $\begin{array}{l}\text { physiotherapy.. } \\
\text { Delay in starting treatment }\end{array}$ & $\cdots$ & 149 (96) & 134 (88) & $\mathrm{p}<0.05$ \\
\hline Duration of treatment $\cdots$ & . & $3 \cdot 0 \pm 0 \cdot 3$ & $3 \cdot 8 \pm 0 \cdot 2$ & $p<0.05$ \\
\hline $\begin{array}{l}\text { (days) } \\
\text { No of hours of treatment }\end{array}$ & 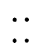 & $\begin{array}{l}49 \cdot 3 \pm 3 \cdot 3 \\
21 \cdot 0 \pm 1 \cdot 5\end{array}$ & $\begin{array}{l}70 \cdot 5 \pm 7 \cdot 8 \\
36 \cdot 4 \pm 4 \cdot 0\end{array}$ & $\begin{array}{l}p<0.05 \\
p<0.001\end{array}$ \\
\hline
\end{tabular}

patients dropped out after randomisation, all in medical units. The mean age of the remaining 307 patients was 73 years. The mean interval from the onset of stroke to admission to the study was 26 hours. There were no differences between patients in the two groups as regards age, sex, social class, marital state, whether they were living alone at home or with members of their family, activities before the stroke, and duration of stroke on admission to the study. The degree of hemiplegia present on admission was remarkably similar in the two groups. Mean duration of hospital stay was $\mathbf{5 5}$ days in the stroke unit and 75 days in medical units; this difference occurred because more patients in the medical units stayed beyond 16 weeks.

Thirty-two patients admitted to medical units were transferred during the acute phase of rehabilitation to rehabilitation or geriatric assessment units, which contained a varied case mix. None of these patients died. Transfers occurred at a mean of 33 days after admission and entailed a further stay in the transfer unit of 75 days. The mean duration of stay of the 72 survivors who remained in the admitting medical units throughout was 96 days.

Table I summarises the outcome assessed at a mean of 60 days after admission to hospital. Seventy-eight (50\%) patients admitted to the stroke unit were assessed as independent compared with 49 (32\%) patients admitted to medical units. When only survivors were considered the proportions of independent patients rose to $62 \%$ $(78 / 125)$ for the stroke unit and $45 \%$ (49/109) for medical units $\left(p<0.05 ; \chi^{2}=6.46, d f=1\right)$. The outcome in patients from medical units who were transferred for further rehabilitation was the same as that in survivors who remained in their admitting medical units, with $47 \%$ being assessed as independent and $53 \%$ as dependent. This excludes five patients from medical units who died after assessment. There were no significant differences $(p>0.05)$ in discharge from hospital between patients in the stroke unit or medical units, equal proportions being discharged home to live alone, with relatives, or into nursing homes or long-stay hospitals. More patients discharged from medical units to live with relatives were dependent compared with those discharged from the stroke unit.

\section{PHYSIOTHERAPY}

A high proportion of patients in both the stroke and medical units were referred for physiotherapy (table II), though the proportion was significantly higher and the delay between admission and the start of physiotherapy significantly shorter $(p<0.05)$ in the stroke unit. Patients in medical units who received physiotherapy had a significantly longer period of treatment $(p<0.05)$ and significantly more hours of treatment $(p<0.001)$. These last two differences occurred because the mean duration of hospital stay was longer for patients in medical units.

Important differences in the use of physiotherapy occurred in patients transferred from medical units compared with those who remained in the admitting hospital. Table III summarises the use of physiotherapy among survivors. The mean number of hours of physiotherapy received by the patients who were transferred was more than double that received by patients in the stroke unit. Seventy-three per cent of the physiotherapy received by this group took place after transfer from the medical unit.

\section{OCCUPATIONAL THERAPY}

Major differences in the use of occupational therapy occurred between groups (table IV). The differences in the proportions of patients receiving any occupational therapy and, particularly, the mean intervals between admission to hospital and the start of occu-

\begin{tabular}{|c|c|c|c|c|c|c|c|c|}
\hline & & & \multirow[b]{2}{*}{$\underset{(n=125)}{\text { Stroke unit }}$} & \multicolumn{2}{|c|}{ Medical units } & \multicolumn{3}{|c|}{ Significance of differences } \\
\hline & & & & $\begin{array}{c}\text { Transferred for } \\
\text { rehabilitation } \\
\quad(\mathbf{n}=32)\end{array}$ & $\begin{array}{l}\text { Remained in } \\
\text { admitting } \\
\text { hospital } \\
(\mathbf{n}=72)\end{array}$ & $\begin{array}{l}\text { Stroke unit } \\
v \\
\text { transferred } \\
\text { patients }\end{array}$ & $\begin{array}{l}\text { Stroke unit } \\
v \\
\text { remaining } \\
\text { patients }\end{array}$ & $\begin{array}{c}\text { Transferred } \\
v \\
\text { remaining } \\
\text { patients }\end{array}$ \\
\hline $\begin{array}{l}\text { No }(\%) \text { of patients receiving any physiotherapy } \\
\text { Mean interval from admission to referral (days) } \\
\text { Mean duration of treatment (days) } \\
\text { Mean No of hours of treatment } \\
\text {. }\end{array}$ & $\begin{array}{l}\cdots \\
\cdots \\
\cdots\end{array}$ & $\because$ & $\begin{array}{r}125(100) \\
2 \cdot 9 \pm 0 \cdot 3 \\
54 \cdot 6 \pm 3 \cdot 6 \\
23 \cdot 5 \pm 1 \cdot 7\end{array}$ & $\begin{array}{l}32(100) \\
4 \cdot 5 \pm 0 \cdot 6 \\
92 \cdot 3 \pm 15 \cdot 3 \\
51 \cdot 4 \pm 6 \cdot 8\end{array}$ & $\begin{array}{c}67(93) \\
3 \cdot 5 \pm 0 \cdot 3 \\
79 \cdot 2 \pm 12 \cdot 4 \\
38 \cdot 5 \pm 6 \cdot 0\end{array}$ & $\begin{array}{c}\text { NS } \\
\mathrm{p}<0.05 \\
\mathrm{p}<0.05 \\
\mathrm{p}<0.001\end{array}$ & $\begin{array}{l}\mathrm{p}<0.05 \\
\mathrm{NS} \\
\mathrm{NS} \\
\mathrm{p}<0.05\end{array}$ & $\begin{array}{l}\text { NS } \\
\text { NS } \\
\text { NS } \\
\text { NS }\end{array}$ \\
\hline
\end{tabular}

*Not significant indicates $p>0.05$. 
TABLE IV-Use of occupational therapy. (Mean results expressed $\pm S E$ )

\begin{tabular}{|c|c|c|c|c|}
\hline & & $\begin{array}{c}\text { Stroke unit } \\
(\mathbf{n}=155)\end{array}$ & $\begin{array}{c}\text { Medical units } \\
(n=152)\end{array}$ & $\begin{array}{l}\text { Significance of } \\
\text { differences }\end{array}$ \\
\hline \multicolumn{2}{|l|}{ No $(\%)$ of patients receiving any } & $136(88)$ & 71 (47) & $\mathrm{n}<0.001$ \\
\hline \multirow{3}{*}{$\begin{array}{l}\text { occupational therapy } \\
\text { Mean delay in starting } \\
\text { treatment (days) } \\
\text { Mean duration of treatment } \\
\text { (days) } \\
\text { Mean No of hours of }\end{array}$} & & & & \\
\hline & . & $6 \cdot 4 \pm 0.5$ & $21 \cdot 1 \pm 3 \cdot 8$ & $p<0.001$ \\
\hline & .. & $46 \cdot 9 \pm 3 \cdot 2$ & $68 \cdot 6 \pm 10 \cdot 3$ & $\mathrm{p}<0.05$ \\
\hline treatment $\quad . . \quad$.. & .. & $33 \cdot 3 \pm 2 \cdot 4$ & $48 \cdot 2 \pm 6 \cdot 1$ & $p<0.05$ \\
\hline
\end{tabular}

pational therapy were striking. Two-thirds of all patients in the stroke unit had begun occupational therapy within one week after admission compared with only $18 \%$ of all admissions to medical units.

The proportion of patients transferred from medical units who received occupational therapy approached the proportion of the survivors in the stroke unit who received such treatment (table V). No less than $89 \%$ of the occupational therapy was provided after the transfer from medical units had occurred.

\section{SPEECH THERAPY}

There were no great differences in the use of speech therapy between groups to match those seen in the use of occupational therapy. Only 20 patients $(13 \%)$ in the stroke unit and $27(18 \%)$ in the medical units received any speech therapy. The mean delay to the start of treatment, mean duration of treatment, and mean number of hours received were nine days, 61 days, and 17 hours respectively for patients in the stroke unit; and six days, 65 days, and 11 hours respectively for patients in medical units.

\section{AIDS AND ADAPTATIONS TO THE HOME}

Prescribing aids to daily living and providing adaptations to patients' homes may have an important bearing on the outcome of stroke rehabilitation. Aids or adaptations were prescribed for 103 survivors (82\%) from the stroke unit during their hospital stay compared with 58 survivors $(56 \%)$ ) from medical units. Patients may derive no benefit from special aids and adaptations if their "accessory" aids such as spectacles, hearing aids, and dentures are not in working order. The proportions of patients in the two groups whose accessory aids were modified or replaced during the acute phase of rehabilitation were $54 \%$ in the stroke unit compared with only $11 \%$ in medical units.

\section{Discussion}

Establishing a stroke unit improved the natural history of stroke by increasing the proportion of patients who were returned to functional independence. The difference in outcome was statistically significant and may be clinically important in the context of the future organisation of services for the care and rehabilitation of elderly people with stroke.

Differences in the use of treatment were found, which might have contributed to the improved outcome of patients admitted to the stroke unit. We cannot say whether the optimum mix of treatment was used to achieve the improvement in functional prognosis. This information can come only from a series of trials examining the impact of different amounts of each com- ponent of stroke rehabilitation in turn, while keeping all the other components constant.

Admission to the stroke unit did not result in the intensive treatment that might have been implied by the creation of such a unit. Nevertheless, almost all the patients in the unit received physiotherapy and occupational therapy, and the delays before starting treatment were shorter. The mean amount of treatment (21 hours of physiotherapy and 33 hours of occupational therapy) received by patients in the stroke unit was quite modest and significantly less than the mean amount of occupational therapy and particularly physiotherapy received by patients in medical units. The small amount of speech therapy given is not surprising, being similar to that found by other workers ${ }^{9}$ and in line with the prevalence of dysphasia found in stroke. ${ }^{10}$

The policy of transferring a selected group of patients from medical units after several weeks and then subjecting them to intensive treatment must be seriously questioned. The failure to improve the functional outcome of this group of patients compared with survivors who remained in admitting medical units throughout is further evidence that treating more of the patients with rehabilitation potential and intervening earlier might be more effective than a late, concentrated effort.

Controlled trials are a way of obtaining comparable data with which to test hypotheses about alternative methods of providing health care, but restrictions in their planning, conduct, and the interpretation of results must be observed. ${ }^{11}$ In particular, the possibility of bias arising through lack of blindness must be recognised. This accounts for the lack of detail of rehabilitation methods that were used in this study. Obtaining this information would have been accompanied by the risk of influencing treatment through a heightened awareness of the study. The difference in mortality between the stroke unit (19\%) and medical units $(28 \%)$ was unexpected and cannot be explained satisfactorily. The difference was not statistically significant $(p>0.05)$ and could therefore have occurred by chance alone. Nevertheless, differences in the distribution of deaths over time occurred between the stroke and medical units that were compatible with a report that stroke units reduce the number of secondary complications due to stroke. ${ }^{12}$ Confirmation of this, however, would have required the kind of direct observation likely to encourage treatment bias in the absence of blindness.

These preliminary results are sufficiently encouraging to suggest that several stroke units should be commissioned in various parts of the country and attempts made to replicate the results. Thereafter, these stroke units might act as centres in which studies to determine the optimum balance of resources for stroke rehabilitation could be undertaken.

We are grateful to the following people for advice and help without which this study could not have been undertaken: the members of the division of medicine, North Lothian District, who agreed to the establishment of the stroke unit and subsequently participated in the study, and their colleagues in the division of medicine, South Lothian District; the staff of the geriatric assessment unit, Royal Victoria Hospital; the staff of the Emergency Bed Bureau, Lothian Health Board; general practitioners; hospital medical records staff, nursing staff, social workers, and therapists; staff in the Information Services Division, Common Services Agency, for numerous ad-hoc tabulations of Scottish hospital inpatient statistics; the Scottish Health Education

TABLE v-Details of occupational therapy according to management of survivors. (Mean results expressed $\pm S E$ )

\begin{tabular}{|c|c|c|c|c|c|c|c|c|}
\hline & & & \multirow[b]{2}{*}{$\begin{array}{l}\text { Stroke unit } \\
(\mathbf{n}=125)\end{array}$} & \multicolumn{2}{|c|}{ Medical units } & \multicolumn{3}{|c|}{ Significance of differences* } \\
\hline & & & & $\begin{array}{l}\text { Transferred for } \\
\text { rehabilitation } \\
\quad(\mathbf{n}=32)\end{array}$ & $\begin{array}{l}\text { Remained in } \\
\text { admitting } \\
\text { hospital } \\
(\mathbf{n}=\mathbf{7 2})\end{array}$ & $\begin{array}{l}\text { Stroke unit } \\
v \\
\text { transferred } \\
\text { patients }\end{array}$ & $\begin{array}{l}\text { Stroke unit } \\
v \\
\text { remaining } \\
\text { patients }\end{array}$ & $\begin{array}{c}\text { Transferred } \\
v \\
\text { remaining } \\
\text { patients }\end{array}$ \\
\hline $\begin{array}{l}\text { No (\%) of patients receiving any occu } \\
\text { Mean interval from admission to refer } \\
\text { Mean duration of treatment (days) . } \\
\text { Mean No of hours of treatment }\end{array}$ & $\begin{array}{l}\text { onal therapy } \\
\text { (days) } \quad \ldots \\
\begin{array}{ll}\ldots & \ldots \\
\ldots & \cdots\end{array}\end{array}$ & $\because$ & $\begin{array}{l}121(97) \\
6 \cdot 5 \pm 0 \cdot 6 \\
49 \cdot 7 \pm 3 \cdot 6 \\
35 \cdot 7 \pm 4 \cdot 4\end{array}$ & $\begin{array}{l}29(91) \\
22 \cdot 6 \pm 4 \cdot 2 \\
78 \cdot 8 \pm 16 \cdot 7 \\
76 \cdot 1 \pm 11 \cdot 6\end{array}$ & $\begin{array}{l}35(49) \\
21 \cdot 2 \pm 6 \cdot 9 \\
69 \cdot 5 \pm 15 \cdot 4 \\
31 \cdot 5 \pm 5 \cdot 5\end{array}$ & $\begin{array}{l}\text { NS } \\
p<0.001 \\
\text { NS } \\
p<0.01\end{array}$ & $\begin{array}{l}p<0.001 \\
p<0.05 \\
\text { NS } \\
\text { NS }\end{array}$ & $\begin{array}{l}p<0.001 \\
\text { NS } \\
\text { NS } \\
p<0.01\end{array}$ \\
\hline
\end{tabular}


Unit; Mr C J A Andrews, department of ergonomics, Napier College of Commerce and Technology, for designing the activities of daily living assessment unit; the department of medicine (Western General Hospital) for providing office accommodation; and the research staff who worked on the project between 1974 and 1979.

We acknowledge the financial support given to the study by the Scottish Home and Health Department and Lothian Regional Council.

Requests for reprints should be addressed to WMG.

\section{References}

1 World Health Organisation. Cerebrovascular diseases: prevention, treatment and rehabilitation. WHO Tech Rep Ser 1971 ; No 469.

2 Joint Committee for Stroke Facilities. Report V. Clinical prevention of stroke. Stroke 1972;3:804-25.

3 Whisnant JP. Indications for medical and surgical therapy for ischaemic stroke. In: Thompson RA, Green JR, eds. Advances in neurology. Vol 16. New York: Raven Press, 1977:133-44.
${ }^{4}$ Kennedy FB, Pozen TJ, Bagelman EH, et al. Stroke intensive care-an appraisal. Am Heart $₹ 1970 ; 80: 188-96$.

5 Joint Committee for Stroke Facilities. Report II. Stroke rehabilitation. Stroke $1972 ; 3: 375-407$.

- Working Group on Strokes, Geriatrics Committee. Report. London: Royal College of Physicians, 1974.

7 Isaacs B. Five years' experience of a stroke unit. Health Bull (Edinb) 1977; $35: 93-8$.

${ }^{8}$ Smith ME, Garraway WM, Akhtar AJ, et al. An assessment unit for measuring the outcome of stroke rehabilitation. British fournal of Occupational Therapy 1977;40:51-3.

- Brocklehurst JC, Andrews K, Richards B, et al. How much physical therapy for patients with stroke ? $\mathrm{Br}$ Med $\mathcal{F} 1978$; i:1307-10.

10 Brust JCM, Shafer SQ, Richter RW, et al. Aphasia in acute stroke. Stroke $1976 ; 7: 167-74$

11 Garraway WM, Prescott RJ. Limitations of the controlled trial in health care. Health Bull (Edinb) 1977;35:131-4.

12 Drake WE, Hamilton MJ, Carlsson $M$, et al. Acute stroke management and patient outcome: the value of neurovascular care units (NCU). Stroke $1973 ; 4: 933-45$.

(Accepted 8 February 1980)

\section{SHORT REPORTS}

\section{Alpha-chain disease diagnosed by rectal biopsy}

Alpha-chain disease is characterised by infiltration of the small intestine with plasma cells that secrete an incomplete alpha heavy chain of the IgA class but no light chains. ${ }^{1}$ The disease has been reported to affect the colon ${ }^{2}$ but this is thought to be uncommon. Diagnosis is usually made by demonstrating free alpha chains in plasma, urine, or jejunal aspirate. ${ }^{34} \mathrm{We}$ describe a case where conventional diagnostic techniques initially failed and the diagnosis was made by immunofluorescence studies. These showed large numbers of plasma cells in the rectal lamina propria that contained alpha chains but no light chains.

\section{Case report}

A 26-year-old Nigerian student who had lived in England for two years presented with a history of four months' colicky abdominal pain, profuse diarrhoea, and weight loss of $25 \mathrm{~kg}$. He had had malaria when aged $10 \mathrm{but}$ had no other relevant past history. He was cachectic, had pronounced finger clubbing but no lymphadenopathy, and a distended abdomen in which no masses could be felt. His haemoglobin concentration was $12.7 \mathrm{~g} / \mathrm{dl}$, white cell count $10.0 \times 10^{\circ} / 1\left(10000 / \mathrm{mm}^{3}\right)$ with a normal differential, and erythrocyte sedimentation rate $10 \mathrm{~mm}$ in the first hour. Serum concentrations were: albumin $27 \mathrm{~g} / \mathrm{dl}$, alkaline phosphatase 52 King-Armstrong units/dl (normal 3-13), immunoglobulin IgG $5.6 \mathrm{~g} / \mathrm{dl}$ (normal 8-18), IgA $0.68 \mathrm{~g} / \mathrm{dl}$ (normal $0.9-4.5$ ), and IgM $0.38 \mathrm{~g} / \mathrm{dl}$ (normal $0.6-2.5$ ). Duodenal aspirate grew Escherichia coli, Klebsiella species, and Veillonella; but no Giardia organisms were found. Faecal fat excretion was greatly raised at $118 \mathrm{mmol}(33 \mathrm{~g}) / 24 \mathrm{~h}$ (normal $<18 \mathrm{mmol}(5 \mathrm{~g}) / 24 \mathrm{~h}$ ). Barium follow-through radiographs showed a malabsorption pattern but no definite mucosal abnormality. Jejunal biopsy showed total villous atrophy, crypt hyperplasia, and a dense plasma cell infiltrate in the lamina propria. Rocket immunophoresis on concentrated urine, plasma, and jejunal aspirate, 4 using a specific anti-alpha antiserum (Mercia Diagnostics), initially failed to show alpha chains. Because of the patient's poor condition jejunal biopsy could not be repeated. Instead, rectal tissue was taken for biopsy and snap frozen in liquid nitrogen. A special stain combination was used containing anti-IgA antibody (heavy chain specific) labelled with tetrarhodamine isothiocyanate (TRITC; red) combined with anti-light chain (kappa and lambda) labelled with fluorescein isothiocyanate (FITC; green).

Strong staining for IgA (heavy chain) was seen in over $90 \%$ of plasma cells while only a few stained (in the same section) for light chains (figure). In a series of biopsies-two rectal, two jejunal, 10 of tonsils, and 35 of lymphomatous nodes-from other patients over $95 \%$ of plasma cells that stained for alpha chain also stained for light chain (G Janossy et al, unpublished observations). A preponderance of plasma cells staining for alpha chain but not for light chain has been seen only in alpha-chain disease. Free alpha chains were subsequently detected after further concentration of a stored urine sample but only after the immunofluorescence studies on the rectal tissue had established the diagnosis. The patient was started on prednisolone $40 \mathrm{mg}$ daily, which was reduced later to $10 \mathrm{mg} /$ day, and oxytetracycline
$500 \mathrm{mg}$ four times a day. He gradually improved. When last seen 12 months after presentation he was asymptomatic and had gained $20 \mathrm{~kg}$ in weight. In a recent repeat jejunal biopsy $70 \%$ of plasma cells contained both alpha and light chains but the remainder still failed to stain for light chains.
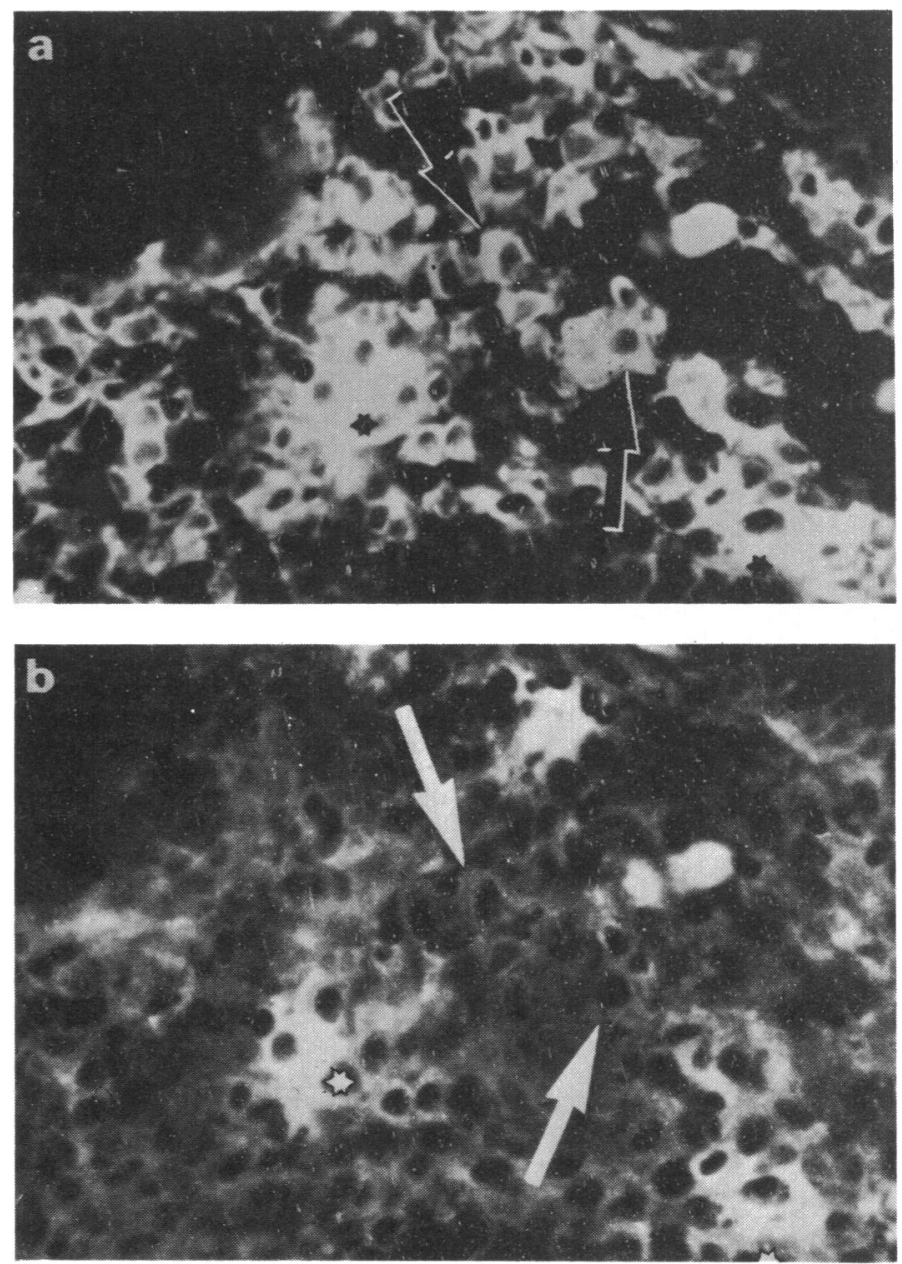

Rectal biopsy section photographed (a) with filters selective for rhodamine (staining for alpha chains), (b) with filters selective for fluorescein (staining for kappa and lambda light chains). Black arrows show two cells staining for alpha chains. White arrows show same cells failing to stain for light chains. Stars mark cell staining normally for both alpha chains and light chains. 